\title{
PneuMod: A Modular Haptic Device with Localized Pressure and Thermal Feedback
}

\author{
Bowen Zhang \\ University of California, Santa Barbara \\ Santa Barbara, USA \\ bowen68@ucsb.edu
}

\author{
Misha Sra \\ University of California, Santa Barbara \\ Santa Barbara, USA \\ sra@cs.ucsb.edu
}

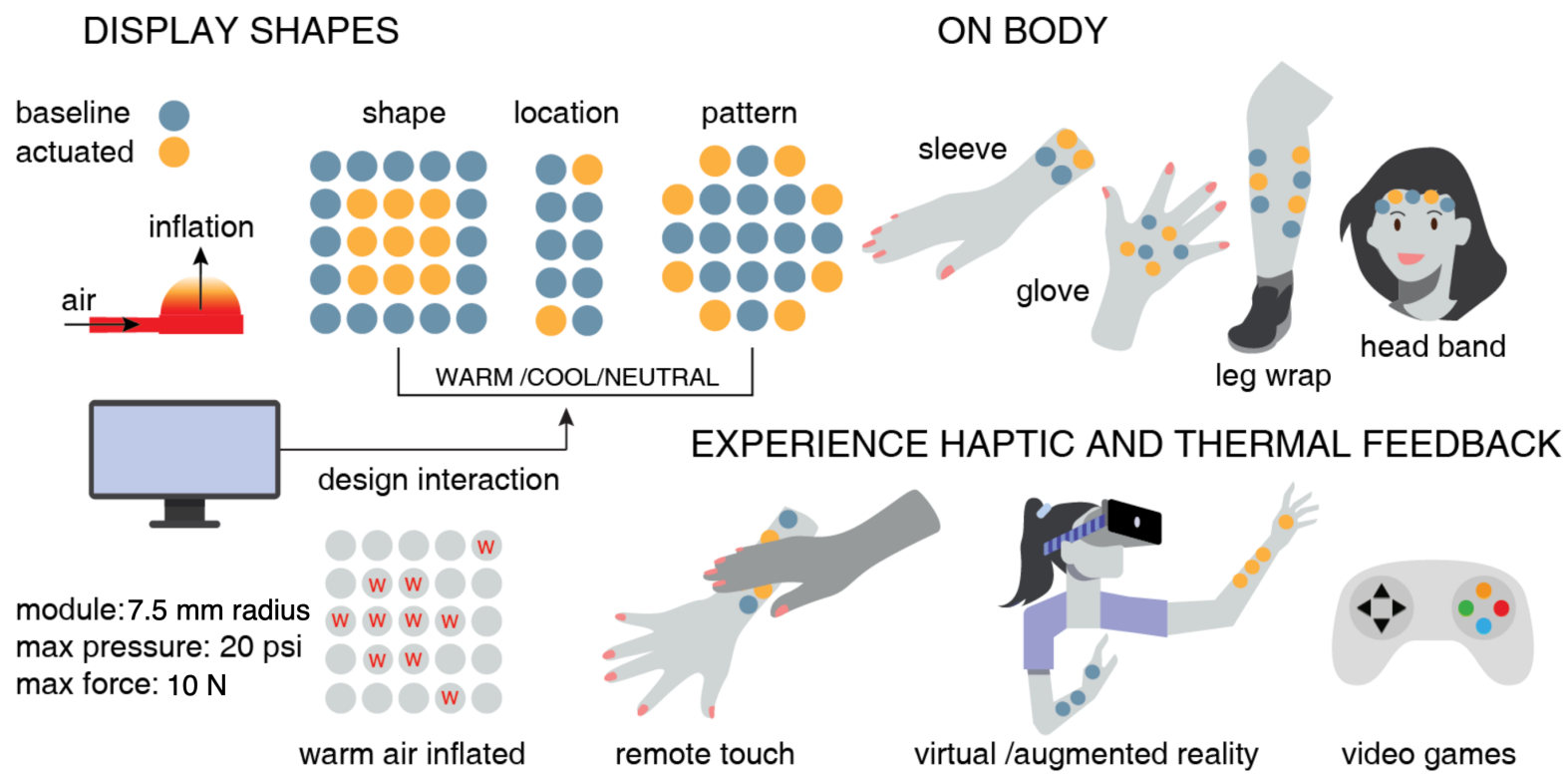

Figure 1: The PneuMod system showing inflatable silicone bubbles that can communicate pressure and thermal cues individually and simultaneously. The modular bubbles can be arranged into different shapes to create haptic feedback sleeves, gloves, or wraps for different parts of the body. The device can be used to communicate touch in virtual reality experiences, video conferencing, movie watching experiences etc.

\begin{abstract}
Humans have tactile sensory organs distributed all over the body. However, haptic devices are often only created for one part (e.g., hands, wrist, or face). We propose PneuMod, a wearable modular haptic device that can simultaneously and independently present pressure and thermal (warm and cold) cues to different parts of the body. The module in PneuMod is a pneumatically-actuated silicone bubble with an integrated Peltier device that can render thermo-pneumatic feedback through shapes, locations, patterns, and motion effects. The modules can be arranged with varying resolutions on fabric to create sleeves, headbands, leg wraps, and other forms that can be worn on multiple parts of the body. In this paper, we describe the system design, the module implementation,

Permission to make digital or hard copies of all or part of this work for personal or classroom use is granted without fee provided that copies are not made or distributed for profit or commercial advantage and that copies bear this notice and the full citation on the first page. Copyrights for components of this work owned by others than the author(s) must be honored. Abstracting with credit is permitted. To copy otherwise, or republish, to post on servers or to redistribute to lists, requires prior specific permission and/or a fee. Request permissions from permissions@acm.org.

VRST '21, December 8-10, 2021, Osaka, Japan

(C) 2021 Copyright held by the owner/author(s). Publication rights licensed to ACM ACM ISBN 978-1-4503-9092-7/21/12 . \$15.00

https://doi.org/10.1145/3489849.3489857
\end{abstract}

and applications for social touch interactions and in-game thermal and pressure feedback.

\section{CCS CONCEPTS}

- Human-centered computing $\rightarrow$ Human computer interaction (HCI); Interaction devices; Haptic devices;

\section{KEYWORDS}

multimodal haptics, pneumatic feedback, thermal feedback, modular device, virtual reality, haptic communication, fabrication

ACM Reference Format:

Bowen Zhang and Misha Sra. 2021. PneuMod: A Modular Haptic Device with Localized Pressure and Thermal Feedback. In 27th ACM Symposium on Virtual Reality Software and Technology (VRST '21), December 8-10, 2021, Osaka, Japan. ACM, New York, NY, USA, 7 pages. https://doi.org/10.1145/ 3489849.3489857

\section{INTRODUCTION}

Touch is a fundamental aspect of our ability to perceive and navigate in the real world. It is also a vital method for communicating emotions. We have recently seen an increase in the the need for social interactions over video conferencing or virtual reality (VR). 
There has been a corresponding increase in demand for haptic feedback devices that can enhance immersiveness in VR and those that can support tactile communication in other forms of digital interactions [22]. Prior work in haptic devices has shown user preference for compression haptic devices over vibration, for communicating touch [29]. However, these devices often lack thermal feedback, despite it being an integral element of touch.

In this work, we propose PneuMod, a modular device that can provide a wide range of controllable, localized pressure and thermal haptic feedback to different parts of the body. It can provide haptic cues independently (pressure or temperature alone) as well as simultaneously. Our thermo-pneumatic actuators are composed of silicon bubbles with Peltier devices. Force and temperature sensors are added to the actuator for feedback control. PneuMod can render three distinct types of haptic feedback: tactile sensation, pressure, and thermal sensation (warmth and coolness). The pneumatically actuated bubbles can be individually controlled for inflation and pressure, speed of inflation, and temperature (both hot and cold). The haptic and thermal stimuli can be rendered in different combinations of shapes, locations, patterns, and motion feel effects (Figure 1), to enable communicating a large variety of distinctly discernible information to the user. Multimodal haptic feedback integrated into VR and other communication systems can be used for many applications including gaming, surgical guidance [30], training [18] and emotional therapy through touch [2].

Pneumatically actuated haptics have primarily been used for providing feedback either to the hand [3] or the torso [5] in VR, often only targeting one part of the body. In contrast, PneuMod's modules can be arranged on fabric to create a variety of wearable form factors that can provide feedback to multiple parts of the body (Figure 3 right). The design of reconfigurable multimodal haptic devices has largely been unexplored in prior work.

In this work, we make the following contributions:

- The design and construction of PneuMod, a modular haptic device that can produce independent as well as simultaneous pressure and thermal sensations.

- Hardware and feedback control algorithms capable of generating pressure, temperature, and combined pressure and temperature cues.

- Applications using PneuMod to communicate social touch interactions and provide in-game thermal and pressure sensations.

To our knowledge, our work is the first system and study that evaluates recognition of pressure and temperature feedback with location, shape, pattern, and motion cues simultaneously.

\section{RELATED WORK}

In this paper, we do not attempt to review the immense field of haptic devices, but instead, highlight a few areas of closest relevance to our work. Comparison with prior work is presented in Table 2 (in Appendix).

\subsection{Pneumatic Interfaces}

Pneumatic actuation is a popular method for enabling tangible and haptic interactions in soft robotics and HCI.

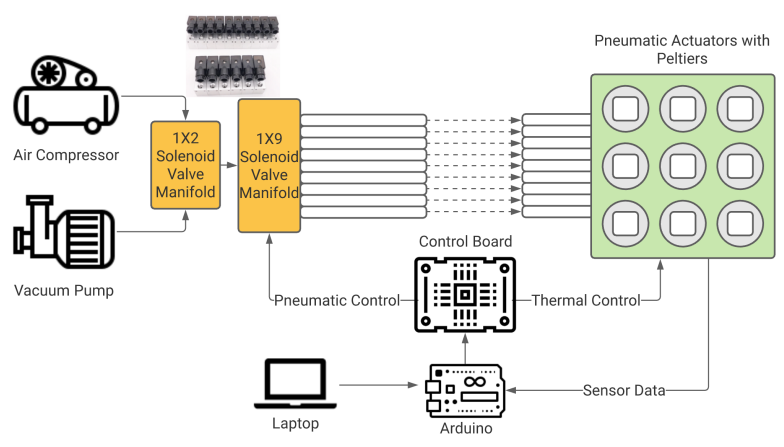

Figure 2: Overview of the PneuMod system.

In HCI, pneumatic actuation has been explored for multitouch displays [28], shape changing input [11], and dynamically changeable soft and ridged buttons [10].

In VR, pneumatic actuation has been used to enhance the sense of immersion through pressure feedback. ThermAirGlove is a VR pneumatic glove with five inflatable airbags on the fingers and the palm to render thermal haptic feedback [3]. Force Jacket [5] uses an array of pneumatically-actuated plastic airbags to provide directed force to the upper body in VR. Inflatable devices have also been used to provide wearable assistive grasping using inflatable silicone actuators [35]. 3D Printed Haptics [7], PNEU-SKIN [32], and Soft LEGO [14] provide modular design using inflatable materials (Table 2 in Appendix). However, only pressure sensation is presented in their work. While we employ pneumatic actuation for our device, our design stands in contrast to aforementioned devices. We present a modular solution for thermal and pressure sensations that allows individual actuators to be arranged in various configurations to create multiple haptic device forms with one system. The system also allows for independently controlling each actuator to provide numerous sensations using thermo-pneumatic shapes, patterns, and feel effects.

\subsection{Thermal Feedback Interfaces}

Thermal sensation has been used in prior work to provide physical information on the environment and objects. Halvey et. al. [9, 33] presented a series of experiments on thermal feedback for the hand.

AmbioTherm is a wearable accessory for headsets that provides thermal and wind stimuli [24]. ThermalBracelet [20] is a wearable wrist-worn device while TherModule [16] can be worn on the wrist/forearm, ankle or neck. EmoJacket [1] provides thermal feedback on the wrist and neck, and vibrotactile feedback on the chest. Since humans can gauge relative temperature simply by touching objects, Lee et al [13] built a soft and bi-functional (cold and hot) thermo-haptic device for VR applications.

\subsection{Multimodal Haptic Feedback}

A 2019 survey by Wang et al. [31] defines multimodal haptic devices as those that are "able to produce multimodal haptic stimuli, including forces, vibration, thermal stimuli, and shape." These devices can be wearable, graspable or touchable [4] and have been shown to significantly alter haptic perception due to their multimodal nature [27]. A miniature fingertip haptic device was presented to render 


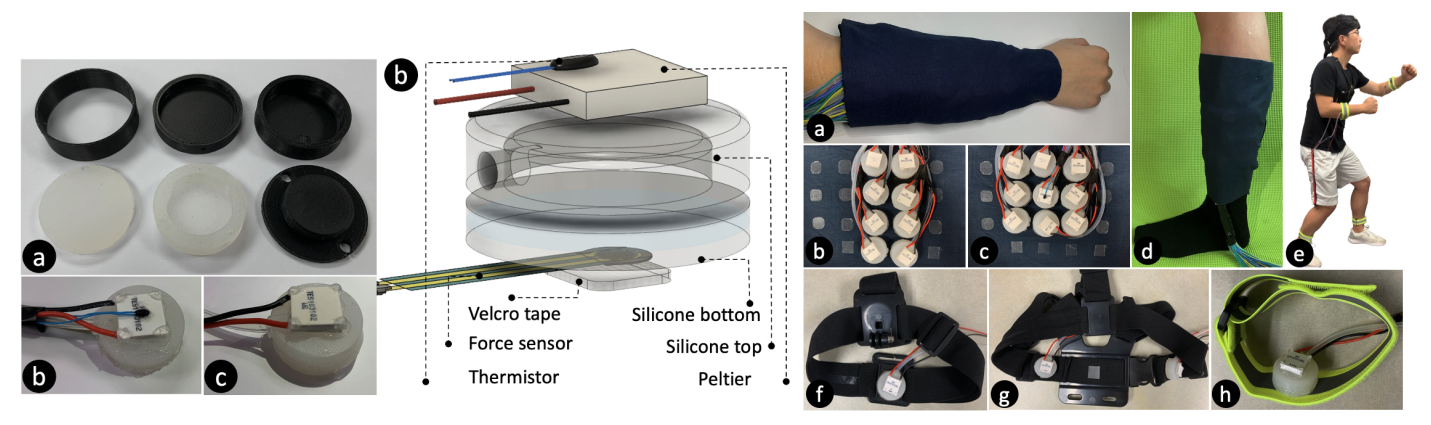

Figure 3: Left: a) Silicone mold and fabrication process. b) Thermo-pneumatic actuator with force and temperature sensors. c) Actuator without sensors. d) 3D design of the actuator. Right: The PneuMod haptic device in two different configurations of bubbles, (b) rectangular and, (c) square, worn on the forearm as shown in (a) and on the lower leg as shown in (d). (e) shows a version of PneuMod for the shooting and fighting game applications worn by a player. (f) An actuator attached to a head band. (g) Two actuators attached to the torso with a chest band. (h) An actuator attached to a band for each wrist and ankle.

force, tactile and thermal feedback [17]. Cai et al. integrated thermal feedback with pneumatics in a glove-based VR device [3]. PATCH provides thermal feedback with simultaneous compression using water in a sleeve worn device [8]. Hot \& Tight is a wrist-mounted device that provides both temperature and pressure sensations though it is unable to present both cues simultaneously [26]. Devices that combine thermal with tactile (compression or pressure) feedback are still limited to either providing uniform sensations without independent control over different parts of the device or not providing the cues simultaneously. In contrast, PneuMod allows independent control over individual actuators for both pressure and temperature sensations enabling a variety of sensations to be communicated simultaneously and quickly.

\section{PNEUMOD}

The PneuMod system combines pneumatic and thermal actuation to deliver pressure and temperature feedback to the user in a wearable form factor. The fundamental building block in PneuMod is a pneumatically actuated air bubble made of silicone with an attached Peltier module. Each actuator can be controlled for the degree of inflation, speed of inflation, and temperature. Multiple bubbles are arranged on fabric to create a multi-point wearable feedback device and can render a broad range of haptic stimuli, including touch, pressure, temperature, and their combinations. Figure 1 illustrates the modular and flexible design concept of our system. The device parameters are presented in Table 1 (in Appendix).

\subsection{System Implementation}

In this section we describe the detailed implementation of one form of our modular device with nine thermo-pneumatic actuators attached to a fabric or a band to be worn on multiple parts of the body. In Section 3.4, we present a few other designs of our device that we built using actuators distributed over the body or clustered on specific parts of the body. The PneuMod system is illustrated in Figure 2. The air bubble array is inflated/deflated using an air compressor tank and an array of solenoid valves for actuating the individual bubbles.

Peltier modules are activated with inflation, and the thermal cues are controlled by changing current direction and input power.
The entire system is controlled using an Arduino Mega 2560 and a custom-designed control board that consists of IRF 540 MOSFETs to turn on/off the solenoid valves. H-Bridge modules (L298N) are embedded to control the Peltiers.

\subsection{Hardware and Software}

The air source is from a compressor tank Tubing in the system has a $2 \mathrm{~mm}$ inside diameter to ensure fast airflow without interfering with wearability. A regulator attached to the outlet allows for manual adjustment of output air pressure. Two solenoid manifolds are used for manipulating the two airflow directions (inflation and deflation) and the individual states of each actuator. The Arduino receives data from the sensors and sends commands to MOSFETs and L298N modules for controlling solenoid valves and Peltier devices.

We designed a user interface (UI) for testing and tuning actuators. Figure 5 (in Appendix) demonstrates the UI for calibration, collecting data, monitoring its behavior, and conducting experiments. It provides two real-time plots for force, displacement, and temperature data allowing further analysis of a single thermo-pneumatic actuator.

\subsection{Pneumatic Actuators and Fabric Wrap}

PneuMod has three main components: 1) a set of silicone thermopneumatic actuators or air bubbles, 2) a control system, and 3) flexible and conformable wrapping layer (a fabric layer for the sleeve, a hair band, or a wrist band) to secure the bubbles and provide support when worn. We designed the thermo-pneumatic bubbles as independent units that can be assembled into different forms on a flexible backing layer to create haptic devices in different shapes. The array of bubbles integrated with fabric or bands can conform to various areas of the body, for example, a forearm sleeve, a leg wrap, or a headband.

Each pneumatic actuator is made of three parts, the bottom silicone air bubble, a Peltier module on top, and sensors (optional). The silicone air bubble is cylindrical in shape with $15 \mathrm{~mm}$ outer diameter and $11 \mathrm{~mm}$ outer height. The inner diameter is $11 \mathrm{~mm}$, and the inner height is $5 \mathrm{~mm}$, providing a $475.2 \mathrm{~mm}^{3}$ chamber (Figure 3 left). The air bubbles are attached to fabric using Velcro so that 
the arrangement, locations, and the number of air bubbles can be adjusted effortlessly (Figure 3 right b, c). For the sleeve, the fabric size is $35 \mathrm{~cm} \times 20 \mathrm{~cm}$ that can wrap around a forearm or lower leg comfortably as shown in Figure 3 right along with two different actuator configurations. The head band, chest band, and wrist band each have one to three actuators attached (Figure 3 right $f, g, h$ ).

\subsection{Form Factors}

With the advantage of the compact actuator size, it is effortless to attach one or more to multiple parts of the body to create different device form factors. For locations like the wrist, arm, chest, forehead, calf, or ankle, actuators attached to bands were used to secure them on the body as demonstrated in Figure 3 right. With these examples, we demonstrate that our device is able to provide both thermal and pressure cues to various body parts simultaneously. With smaller and thinner mold design, the actuator size can be further reduced allowing them to be inserted inside clothing and other items such as gloves, shoes, or shirts to extend the feedback target regions on the body.

\subsection{Fabrication Process}

Each thermo-pneumatic actuator consists of a silicone air compartment, a silicone tube, a Peltier device, a temperature sensor (optional), and a force sensor (optional). The air compartment is made of Smooth-On Dragon Skin 20 silicone ${ }^{1}$. Each actuator is fabricated by casting two separate pieces of silicone into 3D printed molds as shown in Figure 3 left a. The base and the top of the actuator are made separately and then bonded together using Smooth-On Sil-Poxy ${ }^{T M}$ silicone adhesive ${ }^{2}$ to create the final cylindrical shape. The base is a solid piece of silicone and the top is hollow to create the inflatable air chamber. The Peltier device and the force sensor (optional, Interlink FSR $400^{3}$ ) are bonded on the top and bottom of the silicon bubble using silicone adhesive (Figure 3). For more precise temperature control, a thermistor is added between the Peltier and the skin for direct and accurate skin surface readings. The corners of the Peltier are covered by silicone to reduce any discomfort when wearing it. We finally bond a piece of Velcro tape on the bottom of the force sensor and attach each individual bubble to the fabric (Figure 3 left $\mathrm{d}$ ).

\section{APPLICATIONS}

All three applications have multiple possibilities from being VR or non-VR games to being used for VR or non VR real-life distance communication through touch

4.0.1 Sleeve Application: Touching Arm. Touching Arm is a VR experience set in two different environments: the desert and snowy mountains (Figure 4 a). The user wears the PneuMod sleeve ( 8 actuators in total) in order to feel the touch of a virtual hand, which could belong to another person or to a non-player character in the VR experience. This can be used for other related applications like remote touch and other forms of remote casual human contact or remote haptic communication through shapes, patterns and feel effects felt on the arm.

\footnotetext{
${ }^{1}$ https://www.smooth-on.com/products/dragon-skin-20/

${ }^{2}$ https://www.smooth-on.com/product-line/sil-poxy/

${ }^{3}$ https://www.interlinkelectronics.com/fsr-400
}

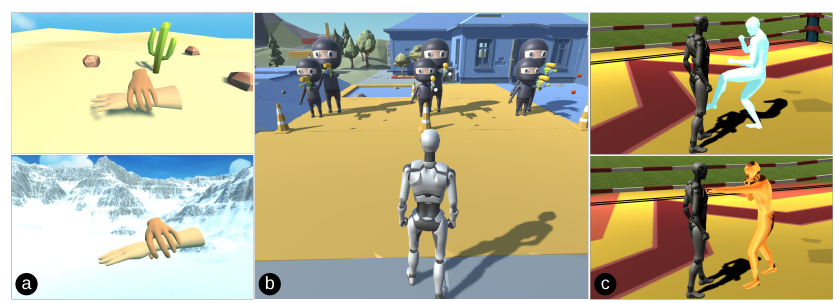

Figure 4: VR applications: a) Touching Arm, b) a shooting game, and c) a fighting game.

4.0.2 Full Body Application: A Shooting Game and A Fighting Game. This is a third-person shooting game that includes three different types bullets: normal bullets, fire balls, and snow balls. The player wears a version of PneuMod, as shown in Figure 3 right. Seven actuators are separately attached to a head band (one actuator), a chest band (two actuators), 2 arm bands (one actuator each), and 2 ankle bands (one actuator each). When the player is hit on the head, the actuator on the headband inflates with warm (fire balls), cool (snow balls), or no temperature (normal bullets). The actuator inflation speeds are independently adjustable as needed. We can imagine this type of feedback also enabling greater engagement in outdoor arena games like Laser Tag.

The PneuMod setup for the fighting game is similar to the shooting game. The player controls their own character to fight with two different enemies, the "iceman" and "fireman" (Figure $4 \mathrm{c}$ ). When hit on different parts of their body, the player feels the pressure from actuators with adjustable hot or cold temperatures.

Beyond the prototype applications, the PneuMod system can be used for other gaming and remote communication applications. For example, it can enable immersive haptic feedback in VR training applications for firefighters or offshore oil rig workers. During training, firefighters or rig workers can directly sense the warmth from a fire, coolness from water, or pressure feedback when hitting or hit by any objects. The system offers great potential for remote communication (e.g., social touch over distance) through haptic signals across the whole body. Transferring music beats through pressure and temperature to different parts of the body has the potential to improve immersion in music games (e.g., the popular VR game Beat Saber) or help learn to play musical instruments. Lastly, remote touch on the arms or hands can offer guided assistance to users for task completion in augmented reality.

\section{LIMITATIONS AND FUTURE WORK}

While PneuMod can provide simultaneous renderings of both pneumatic and thermal cues. There are some limitations that are worth addressing in future work. With the system consisting of solenoid valves and an air compressor, the overall system set-up can be bulky. As the number of actuators increases, wires and tubing can become inconvenient and better heat dissipation of Peltier devices is needed. In the future, we plan to explore the design of a soft circuit layer under the air bubbles with a wireless module to eliminate some of the wires. We also plan on building on the results of our preliminary user study $(n=7)$ which showed that a user can differentiate between different shapes, patterns, motions, and thermal effects of actuation while wearing the device as a sleeve on the forearm. 


\section{CONCLUSION}

This paper introduced PneuMod, a modular haptic device that can render tactile, force, and thermal sensations individually and simultaneously. The device modules or distinct pneumatic actuators can be arranged in any configuration on fabric and worn as sleeves, leg wraps, headbands or other forms. The system has a temperature range of $15{ }^{\circ} \mathrm{C}$ to $40{ }^{\circ} \mathrm{C}$ and an actuation rate of $7 \mathrm{~Hz}$ which is higher than other pneumatic devices. Our applications show that PneuMod has the potential to offer novel multimodal haptic stimuli not only in immersive VR experiences but also in other forms of digital communication.

\section{REFERENCES}

[1] Faisal Arafsha, Kazi Masudul Alam, and Abdulmotaleb El Saddik. 2012. EmoJacket Consumer centric wearable affective jacket to enhance emotional immersion. In 2012 international conference on innovations in information technology (IIT). IEEE, 350-355.

[2] Leonardo Bonanni, Cati Vaucelle, Jeff Lieberman, and Orit Zuckerman. 2006 Taptap: a haptic wearable for asynchronous distributed touch therapy. In $\mathrm{CHI} 06$ extended abstracts on Human factors in computing systems. 580-585.

[3] Shaoyu Cai, Pingchuan Ke, Takuji Narumi, and Kening Zhu. 2020. ThermAir Glove: A Pneumatic Glove for Thermal Perception and Material Identification in Virtual Reality. In 2020 IEEE Conference on Virtual Reality and 3D User Interfaces (VR). IEEE, 248-257.

[4] Heather Culbertson, Samuel B Schorr, and Allison M Okamura. 2018. Haptics: The present and future of artificial touch sensation. Annual Review of Control, Robotics, and Autonomous Systems 1 (2018), 385-409.

[5] Alexandra Delazio, Ken Nakagaki, Roberta L Klatzky, Scott E Hudson, Jill Fain Lehman, and Alanson P Sample. 2018. Force jacket: Pneumatically-actuated jacket for embodied haptic experiences. In Proceedings of the 2018 CHI Conference on Human Factors in Computing Systems. 1-12.

[6] Shreyosi Endow, Hedieh Moradi, Anvay Srivastava, Esau G Noya, and Cesar Torres. 2021. Compressables: A Haptic Prototyping Toolkit for Wearable Compression-Based Interfaces. In Designing Interactive Systems Conference 2021 (Virtual Event, USA) (DIS '21). Association for Computing Machinery, New York, NY, USA, 1101-1114. https://doi.org/10.1145/3461778.3462057

[7] Yuan-Ling Feng, Roshan Lalintha Peiris, Charith Lasantha Fernando, and Kouta Minamizawa. 2018. 3D Printed Haptics: Creating Pneumatic Haptic Display Based on 3D Printed Airbags. In Haptics: Science, Technology, and Applications, Domenico Prattichizzo, Hiroyuki Shinoda, Hong Z. Tan, Emanuele Ruffaldi, and Antonio Frisoli (Eds.). Springer International Publishing, Cham, 180-192.

[8] Dustin T Goetz, David K Owusu-Antwi, and Heather Culbertson. 2020. PATCH Pump-Actuated Thermal Compression Haptics. In 2020 IEEE Haptics Symposium (HAPTICS). IEEE, 643-649.

[9] Martin Halvey, Graham Wilson, Stephen Brewster, and Stephen Hughes. 2012. " Baby it's cold outside" the influence of ambient temperature and humidity on thermal feedback. In Proceedings of the SIGCHI Conference on Human Factors in Computing Systems. 715-724.

[10] Chris Harrison and Scott E Hudson. 2009. Providing dynamically changeable physical buttons on a visual display. In Proceedings of the SIGCHI Conference on Human Factors in Computing Systems. 299-308.

[11] Seoktae Kim, Hyunjung Kim, Boram Lee, Tek-Jin Nam, and Woohun Lee. 2008. Inflatable mouse: volume-adjustable mouse with air-pressure-sensitive input and haptic feedback. In Proceedings of the SIGCHI Conference on Human Factors in Computing Systems. 211-224.

[12] Seung-Won Kim, Sung Hee Kim, Choong Sun Kim, Kyoungsoo Yi, Jun-Sik Kim, Byung Jin Cho, and Youngsu Cha. 2020. Thermal display glove for interacting with virtual reality. Scientific Reports 10, 1 (09 Jul 2020), 11403. https://doi.org/ 10.1038/s41598-020-68362-y

[13] Jinwoo Lee, Heayoun Sul, Wonha Lee, Kyung Rok Pyun, Inho Ha, Dongkwan Kim, Hyojoon Park, Hyeonjin Eom, Yeosang Yoon, Jinwook Jung, et al. 2020. Stretchable Skin-Like Cooling/Heating Device for Reconstruction of Artificial Thermal Sensation in Virtual Reality. Advanced Functional Materials (2020), 1909171.

[14] Jun-Young Lee, Jaemin Eom, Woo-Young Choi, and Kyu-Jin Cho. 2018. Soft LEGO: Bottom-Up Design Platform for Soft Robotics. In 2018 IEEE/RSF International Conference on Intelligent Robots and Systems (IROS). 7513-7520. https://doi.org/ 10.1109/IROS.2018.8593546

[15] Yuhu Liu, Satoshi Nishikawa, Young ah Seong, Ryuma Niiyama, and Yasuo Kuniyoshi. 2021. ThermoCaress: A Wearable Haptic Device with Illusory Moving Thermal Stimulation. Association for Computing Machinery, New York, NY, USA https://doi.org/10.1145/3411764.3445777
[16] Tomosuke Maeda and Tetsuo Kurahashi. 2019. Thermodule: Wearable and modular thermal feedback system based on a wireless platform. In Proceedings of the 10th Augmented Human International Conference 2019. 1-8.

[17] Takaki Murakami, Tanner Person, Charith Lasantha Fernando, and Kouta Minamizawa. 2017. Altered touch: miniature haptic display with force, thermal and tactile feedback for augmented haptics. In ACM SIGGRAPH 2017 Posters. 1-2.

[18] Lucian Panait, Ehab Akkary, Robert L Bell, Kurt E Roberts, Stanley J Dudrick, and Andrew J Duffy. 2009. The role of haptic feedback in laparoscopic simulation training. Journal of Surgical Research 156, 2 (2009), 312-316.

[19] Athina Papadopoulou, Jaclyn Berry, Terry Knight, and Rosalind Picard. 2019. Affective sleeve: wearable materials with haptic action for promoting calmness. In International Conference on Human-Computer Interaction. Springer, 304-319.

[20] Roshan Lalitha Peiris, Yuan-Ling Feng, Liwei Chan, and Kouta Minamizawa. 2019. Thermalbracelet: Exploring thermal haptic feedback around the wrist. In Proceedings of the 2019 CHI Conference on Human Factors in Computing Systems. $1-11$.

[21] Roshan Lalintha Peiris, Wei Peng, Zikun Chen, Liwei Chan, and Kouta Minamizawa. 2017. Thermovr: Exploring integrated thermal haptic feedback with head mounted displays. In Proceedings of the 2017 CHI Conference on Human Factors in Computing Systems. 5452-5456.

[22] Devon Powers and David Parisi. 2020. The hype, haplessness and hope of haptics in the COVID-19 era. Retrieved April 4, 2021 from https://techcrunch.com/2020/ 07/28/the-hype-haplessness-and-hope-of-haptics-in-the-covid-19-era/

[23] Michael Raitor, Julie M. Walker, Allison M. Okamura, and Heather Culbertson. 2017. WRAP: Wearable, restricted-aperture pneumatics for haptic guidance. In Proceedings - IEEE International Conference on Robotics and Automation. Institute of Electrical and Electronics Engineers Inc., 427-432. https://doi.org/10.1109/ ICRA.2017.7989055

[24] Nimesha Ranasinghe, Pravar Jain, Shienny Karwita, David Tolley, and Ellen YiLuen Do. 2017. Ambiotherm: enhancing sense of presence in virtual reality by simulating real-world environmental conditions. In Proceedings of the $2017 \mathrm{CHI}$ Conference on Human Factors in Computing Systems. 1731-1742.

[25] Youngbo Aram Shim, Jaeyeon Lee, and Geehyuk Lee. 2018. Exploring Multimodal Watch-Back Tactile Display Using Wind and Vibration (CHI EA '18). Association for Computing Machinery, New York, NY, USA, 1-3. https://doi.org/10.1145/ 3170427.3186488

[26] Sunghyun Song, Geeyoung Noh, Junwoo Yoo, Ian Oakley, Jundong Cho, and Andrea Bianchi. 2015. Hot \& tight: exploring thermo and squeeze cues recognition on wrist wearables. In Proceedings of the 2015 ACM International Symposium on Wearable Computers. 39-42.

[27] MA SRINIVASSAN. 1996. The impact of visual information on the haptic perception of stiffness in virtual environments. Proc. ASME Dynamic Systems and Control Div. 58 (1996), 555-559.

[28] Andrew Stevenson, Christopher Perez, and Roel Vertegaal. 2010. An inflatable hemispherical multi-touch display. In Proceedings of the fifth international conference on Tangible, embedded, and embodied interaction. 289-292.

[29] Katja Suhonen, Kaisa Väänänen-Vainio-Mattila, and Kalle Mäkelä. 2012. User experiences and expectations of vibrotactile, thermal and squeeze feedback in interpersonal communication. In The 26th BCS Conference on Human Computer Interaction 26. 205-214.

[30] Olivier AJ Van der Meijden and Marlies P Schijven. 2009. The value of haptic feedback in conventional and robot-assisted minimal invasive surgery and virtual reality training: a current review. Surgical endoscopy 23, 6 (2009), 1180-1190.

[31] Dangxiao Wang, Kouhei Ohnishi, and Weiliang Xu. 2019. Multimodal haptic display for virtual reality: A survey. IEEE Transactions on Industrial Electronics 67, 1 (2019), 610-623.

[32] Yujie Wang and Marcela Godoy. 2021. PNEU-SKIN: A Haptic Social Interface with Inflatable Fabrics. In Proceedings of the 26th International Conference of the Association for Computer-Aided Architectural Design Research. 713-722.

[33] Graham Wilson, Stephen Brewster, Martin Halvey, and Stephen Hughes. 2012. Thermal icons: evaluating structured thermal feedback for mobile interaction. In Proceedings of the 14th international conference on Human-computer interaction with mobile devices and services. 309-312.

[34] Jiayi Xu, Yoshihiro Kuroda, Shunsuke Yoshimoto, and Osamu Oshiro. 2019. Noncontact cold thermal display by controlling low-temperature air flow generated with vortex tube. In 2019 IEEE World Haptics Conference (WHC). IEEE, 133-138.

[35] Xinlei Zhang, Ali Shtarbanov, Jiani Zeng, Valerie K Chen, V Michael Bove, Pattie Maes, and Jun Rekimoto. 2019. Bubble: Wearable Assistive Grasping Augmentation Based on Soft Inflatables. In Extended Abstracts of the 2019 CHI Conference on Human Factors in Computing Systems. 1-6.

[36] Mengjia Zhu, Amirhossein H Memar, Aakar Gupta, Majed Samad, Priyanshu Agarwal, Yon Visell, Sean J Keller, and Nicholas Colonnese. 2020. PneuSleeve: In-fabric Multimodal Actuation and Sensing in a Soft, Compact, and Expressive Haptic Sleeve. In Proceedings of the 2020 CHI Conference on Human Factors in Computing Systems. 1-12. 


\section{A APPENDIX}

Table 1: PneuMod parameters.

\begin{tabular}{ll}
\hline PneuMod Parameters & Values \\
\hline Fabric size $(\mathrm{cm})$ & $35 \times 20$ \\
Radius $\times$ Height $(\mathrm{mm})$ & $5 \times 16$ \\
Maximum Height After Inflation $(\mathrm{mm})$ & 40 \\
Maximum force applied $(\mathrm{N})$ & 10 \\
Max Air Inlet Pressure $(\mathrm{psi})$ & 20 \\
Maximum vibration frequency $(\mathrm{Hz})$ & 7 \\
Temperature Range $\left({ }^{\circ} \mathrm{C}\right)$ & $15-40$ \\
Overall Thickness with Fabric $(\mathrm{mm})$ & 20 \\
Solenoid reaction time $(\mathrm{ms})$ & 20 \\
\hline
\end{tabular}

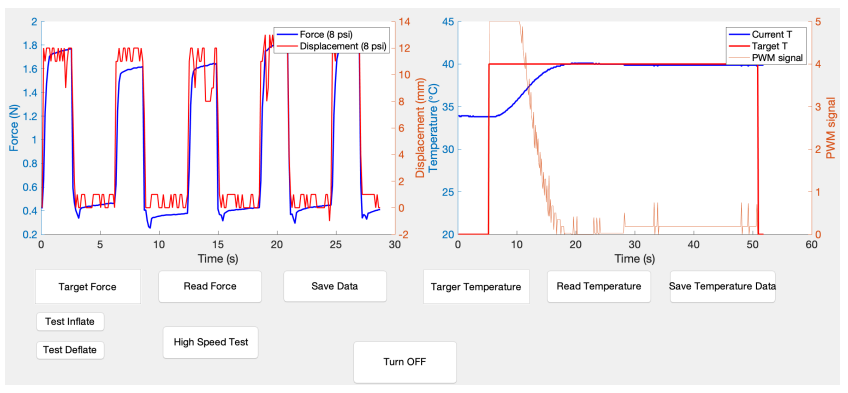

Figure 5: UI for researchers to monitor the behavior of a thermopneumatic actuator. 
Table 2: Related research and differences from PneuMod

\begin{tabular}{|c|c|c|c|c|c|}
\hline Study & Objective & $\begin{array}{l}\text { Form Fac- } \\
\text { tor }\end{array}$ & Actuator & Features & Differences from our work \\
\hline $\begin{array}{l}\text { PATCH by } \\
\text { Goetz et } \\
\text { al. [8] }\end{array}$ & $\begin{array}{l}\text { A hydraulic sleeve that can } \\
\text { render thermal and pressure } \\
\text { cues }\end{array}$ & $\begin{array}{l}\text { Sleeve; Hy- } \\
\text { draulic }\end{array}$ & $\begin{array}{l}\text { Fabric } \\
\text { pouches }\end{array}$ & $\begin{array}{l}\text { Generates } \\
\text { both pressure } \\
\text { and thermal } \\
\text { sensations }\end{array}$ & $\begin{array}{l}\text { Single form factor; The pressure and thermal sensa- } \\
\text { tions can only be applied uniformly to a large skin } \\
\text { area. }\end{array}$ \\
\hline $\begin{array}{ll}\mathrm{Xu} & \text { et } \\
\text { al. [34] }\end{array}$ & $\begin{array}{l}\text { A no-contact cold thermal } \\
\text { display using airflow }\end{array}$ & $\begin{array}{l}\text { No-contact } \\
\text { cold air; } \\
\text { Pneumatic }\end{array}$ & Vortex tube & $\begin{array}{l}\text { Temperature is } \\
\text { controlled by } \\
\text { airflow }\end{array}$ & $\begin{array}{l}\text { Contactless, the user can feel the airflow from the } \\
\text { vortex tube. Only temperature feedback and only } \\
\text { coldness cues. }\end{array}$ \\
\hline $\begin{array}{l}\text { Kim et } \\
\text { al. [12] }\end{array}$ & $\begin{array}{l}\text { A thermal display glove that } \\
\text { brings bidirectional thermal } \\
\text { stimulus to the skin }\end{array}$ & $\begin{array}{l}\text { Glove; Elec- } \\
\text { tric }\end{array}$ & $\begin{array}{l}\text { Thermo- } \\
\text { electric } \\
\text { devices }\end{array}$ & $\begin{array}{l}\text { no pressure } \\
\text { feedback }\end{array}$ & Single form factor; no pressure feedback. \\
\hline $\begin{array}{lr}\text { WRAP } & \text { by } \\
\text { Raitor } & \text { et } \\
\text { al. [23] } & \end{array}$ & $\begin{array}{l}\text { A wearable, pneumatically } \\
\text { actuated haptic feedback de- } \\
\text { vice }\end{array}$ & $\begin{array}{l}\text { Wrist band; } \\
\text { Pneumatic }\end{array}$ & $\begin{array}{l}\text { Thermo- } \\
\text { plastic } \\
\text { pneumatic } \\
\text { actuator }\end{array}$ & $\begin{array}{l}\text { Only generates } \\
\text { pressure sensa- } \\
\text { tion }\end{array}$ & No thermal feedback. \\
\hline $\begin{array}{lr}\text { Hot } & \& \\
\text { Tight } & \text { by } \\
\text { Song } & \text { et } \\
\text { al. [26] } & \\
\end{array}$ & $\begin{array}{l}\text { A wristband that generates } \\
\text { thermal and squeeze feed- } \\
\text { back }\end{array}$ & $\begin{array}{l}\text { Wrist band; } \\
\text { Electric }\end{array}$ & $\begin{array}{l}\text { Motors } \\
\text { and Peltier } \\
\text { devices }\end{array}$ & $\begin{array}{l}\text { Thermal } \\
\text { and squeeze } \\
\text { feedback. }\end{array}$ & $\begin{array}{l}\text { Single form factor; it can provide pressure but only } \\
\text { squeeze feedback on the whole wrist. Cannot provide } \\
\text { pressure and thermal cues simultaneously. }\end{array}$ \\
\hline $\begin{array}{l}\text { Force } \\
\text { Jacket by } \\
\text { Delazio et } \\
\text { al. [5] }\end{array}$ & $\begin{array}{l}\text { A jacket with inflatable plas- } \\
\text { tic pockets inside to provide } \\
\text { pressure feedback }\end{array}$ & $\begin{array}{l}\text { Jacket; } \\
\text { Pneumatic }\end{array}$ & $\begin{array}{l}\text { Compressed } \\
\text { air }\end{array}$ & $\begin{array}{l}\text { Only gener- } \\
\text { ates pressure } \\
\text { feedback }\end{array}$ & Large pockets; no thermal feedback. \\
\hline $\begin{array}{l}\text { Papado- } \\
\text { poulou et } \\
\text { al. [19] }\end{array}$ & $\begin{array}{l}\text { Inserted Nitinol wires to } \\
\text { create slight pressure and } \\
\text { warmth }\end{array}$ & $\begin{array}{l}\text { Sleeve; } \\
\text { Electric }\end{array}$ & $\begin{array}{l}\text { Nitinol- } \\
\text { wires }\end{array}$ & $\begin{array}{l}\text { Slight thermal } \\
\text { and squeeze } \\
\text { feedback }\end{array}$ & $\begin{array}{l}\text { This work only provides slight pressure around the } \\
\text { arm, and there is no coolness feedback. The device } \\
\text { has a single form factor vs our modular system. }\end{array}$ \\
\hline 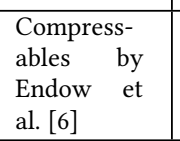 & $\begin{array}{l}\text { A haptic prototyping toolkit } \\
\text { for wearable compression- } \\
\text { based interfaces }\end{array}$ & $\begin{array}{l}\text { Braces; } \\
\text { Pneumatic }\end{array}$ & $\begin{array}{l}\text { Air pump } \\
\text { motors }\end{array}$ & $\begin{array}{l}\text { Only gener- } \\
\text { ates pressure } \\
\text { feedback }\end{array}$ & $\begin{array}{l}\text { Air bubbles cannot be controlled individually; low } \\
\text { pressure and inflation speed; no thermal feedback. }\end{array}$ \\
\hline $\begin{array}{l}\text { TherModule } \\
\text { by Maeda } \\
\text { and Kura- } \\
\text { hashi [16] }\end{array}$ & $\begin{array}{l}\text { A wearable and modular } \\
\text { Thermal feedback system }\end{array}$ & $\begin{array}{l}\text { Wrist band; } \\
\text { Electric }\end{array}$ & $\begin{array}{l}\text { Peltier } \\
\text { devices }\end{array}$ & $\begin{array}{l}\text { Modular but } \\
\text { only gener- } \\
\text { ates thermal } \\
\text { feedback }\end{array}$ & $\begin{array}{l}\text { No pressure feedback; can only be used on arms and } \\
\text { legs }\end{array}$ \\
\hline $\begin{array}{l}\text { ThermoVR } \\
\text { by Peiris et } \\
\text { al. [21] }\end{array}$ & $\begin{array}{l}\text { A Thermal feedback device } \\
\text { that is integrated in the head } \\
\text { mounted display }\end{array}$ & $\begin{array}{l}\text { Head } \\
\text { mounted } \\
\text { display; } \\
\text { Electric } \\
\end{array}$ & $\begin{array}{l}\text { Peltier } \\
\text { devices }\end{array}$ & $\begin{array}{l}\text { Modular but } \\
\text { only gener- } \\
\text { ates thermal } \\
\text { feedback }\end{array}$ & $\begin{array}{l}\text { The locations of the device and the form factor are } \\
\text { fixed; no pressure feedback. }\end{array}$ \\
\hline $\begin{array}{l}\text { ThermoCaress } \\
\text { by Liu et } \\
\text { al. [15] }\end{array}$ & $\begin{array}{l}\text { Inflatable pouches for pres- } \\
\text { sure and thermal feedback }\end{array}$ & $\begin{array}{l}\text { Sleeve; Hy- } \\
\text { draulic and } \\
\text { pneumatic }\end{array}$ & Pouches & $\begin{array}{l}\text { Modular, pres- } \\
\text { sure, and ther- } \\
\text { mal feedback }\end{array}$ & $\begin{array}{l}\text { The locations of the device and the form factor are } \\
\text { fixed; no pressure feedback. }\end{array}$ \\
\hline $\begin{array}{l}\text { PneuSleeve } \\
\text { by Zhu et } \\
\text { al. [36] }\end{array}$ & $\begin{array}{l}\text { fabric-based sleeve that can } \\
\text { render multimodal haptic } \\
\text { stimuli }\end{array}$ & $\begin{array}{l}\text { Sleeve; } \\
\text { Pneumatic }\end{array}$ & Pouches & $\begin{array}{l}\text { compression, } \\
\text { skin stretch, } \\
\text { and vibration }\end{array}$ & Single form factor; no thermal feedback. \\
\hline $\begin{array}{l}\text { 3D Printed } \\
\text { Haptics } \\
\text { by Feng et } \\
\text { al. [36] } \\
\end{array}$ & $\begin{array}{l}\text { 3D printed airbags on finger- } \\
\text { tips for pressure and vibra- } \\
\text { tion }\end{array}$ & $\begin{array}{l}\text { Airbags on } \\
\text { fingertips }\end{array}$ & Airbags & $\begin{array}{l}\text { Compression } \\
\text { and vibration }\end{array}$ & No thermal feedback. \\
\hline $\begin{array}{l}\text { PNEU-SKIN } \\
\text { by Wang et } \\
\text { al. [32] }\end{array}$ & $\begin{array}{l}\text { A pneumatic wearable to cre- } \\
\text { ate soft boundaries }\end{array}$ & Clothing & $\begin{array}{l}\text { Inflatable } \\
\text { fabrics }\end{array}$ & $\begin{array}{l}\text { Clothing that } \\
\text { inflates to } \\
\text { increase size }\end{array}$ & Limited tactile stimuli and no thermal feedback. \\
\hline $\begin{array}{l}\text { Soft LEGO } \\
\text { by Lee et } \\
\text { al. [14] }\end{array}$ & $\begin{array}{l}\text { A design platform for soft ro- } \\
\text { botics with three soft bricks }\end{array}$ & $\begin{array}{l}\text { LEGO } \\
\text { bricks }\end{array}$ & Pneumatic & $\begin{array}{l}\text { Bottom-up } \\
\text { design plat- } \\
\text { form for soft } \\
\text { robotics }\end{array}$ & Not for generating haptic feedback \\
\hline $\begin{array}{l}\text { Watch-back } \\
\text { Tactile Dis- } \\
\text { play by Shim } \\
\text { et al. [25] }\end{array}$ & $\begin{array}{l}\text { A wind-vibration tactile dis- } \\
\text { play for smart watches }\end{array}$ & $\begin{array}{l}\text { Watch- } \\
\text { back }\end{array}$ & $\begin{array}{l}\text { A vibration } \\
\text { motor and a } \\
\text { fan }\end{array}$ & $\begin{array}{l}\text { wind-vibration } \\
\text { tactile display } \\
\text { on the back of } \\
\text { a watch }\end{array}$ & Limited thermal feedback and no pressure feedback \\
\hline
\end{tabular}

